With sucrose as the substrate, 30 per cent of the material was recovered as carbon dioxide, and 17 per cent each as starch, sucrose, fructose and glucose. With invert sugar as the substrate, 30 per cent was again recovered as carbon dioxide, only 20 per cent as the three sugars together, and 50 per cent as starch.

Whichever hexose was initially labelled and whether the sugar was supplied as sucrose or hexose, the relative specific activities of starch and sucrose in the leaf disks and of the carbon dioxide evolved were equal or nearly equal to that of the sugar supplied.

With sucrose as the substrate the sucrose in the disks retained its asymmetry of label, and free hexoses produced were similarly asymmetrically labelled. When invert sugar was the substrate, the sucrose synthesized was strongly labelled in both moieties, as also were the free hexoses.

It is concluded that fructose and glucose free or combined in sucrose were equally available for starch synthesis and carbon dioxide formation, and that there can be no question of preferential utilization of one or other hexose. Starch and carbon dioxide must arise from a common source in which readily formed derivatives of the hexoses are rapidly equilibrated. Free hexose cannot participate directly in either sucrose or starch synthesis. Accumulation of sugar not immediately metabolized and inversion of sucrose take place at a site remote from the common pool.

\section{MARINE BIOLOGICAL RESEARCH}

T

HE first number of Vol. 34 of the Journal of the Marine Biological Association of the United Kingdom contains ten papers on a variety of marine topics. It commences with an obituary notice of one to whom marine biology owes a very great deal, the late Dr. George Parker Bidder, who died in his ninety-first year last December; he was the last of those connected with the early development and struggle for existence of the Marine Biological Association and its first honorary member. There is a characteristic photograph of him as frontispiece.

In the first of the ten papers, Dr. John R. Baker, working under the auspices of the Universities' Federation for Animal Welfare, describes a method for the humane killing of crabs by piercing the brain with an awl through the sternum of the segment of the first antenna and the ventral nerve mass through the depression at the posterior end of the sternum of the chela-bearing segment. The method can be learned quickly by the fishmonger and canner, and avoids autotomy of the appendages.

Dr. H. A. Cole and Mr. D. A. Hancock record the presence of a small parasitic gastropod in oysters from the River Colne in Essex, Odostomia eulimoides, formerly known only from Pecten maximus and Chlamys opercularis. Odostomia attacks the mantle edge of the oyster, causing the formation of a mantle pocket, later of a shell pocket, with thickening of the mantle and shell substance over the pocket, the malfornation being visible externally. In severe cases, involving the presence of a number of parasites, the irritation may spread inwards to the adductor muscle, and the deposition of brown shell material on this muscle causes the shell to gape, with resulting suffocation and death. The parasite occurs in the
River Crouch in considerable numbers, in other rivers of Essex, and also at Salcombe, Devon, where Chrysallida obtusa Brown is here recorded for the first time in oysters. In North Wales, Dr. Knight Jones found Odostomia scalaris in mussels. No methods of control are known.

A detailed account of feeding and digestion in terebellids, with special reference to Amphitrite johnstoni, and a comparison between this and other members of the family are given by Dr. R. Phillips Dales. Food is collected by ciliary action along the groove on each of the tentacles and, wrapped in mucus, is conveyed to the lips and thence, by an elaborate series of rolling movements, to the mouth. Strong amylase activity, weak protease and lipase activity occur in the fore-stomach, strong enzyme secretion of all three in the fore-intestine and, between the two, mixing of the food by muscular action of the hind-stomach. Absorption takes place in the foreintestine and anterior part of the hind-intestine. While the structure of the gut and the digestive process are similar in all terebellids, the lips and feeding habits vary in different genera.

Dr. J. E. Morton and Dr. N. A. Holme record the discovery of large numbers of the tectibranch Akera bullata in a sea-water tank in the Naval Dockyard at Devonport, the first record for the Plymouth area. The animals were feeding on the thick growth of green algae growing on the sides of the tank and were breeding freely, the majority, however, dying after spawning. A study of its structure leads the authors to the conclusion that Akera ought to be removed from the Bullomorpha and placed in the Aplysiomorpha. A good account is given of its swimming habits, with outline diagrams based on a film of the living animal taken by Mr. F. A. J. Armstrong, and Dr. D. P. Wilson adds beautiful photographs of this marine 'ballet dancer'. Dr. Morton also contributes a paper on the structure and ecology of the minute marine pulmonate, Otina otis. This limpet-like form lives in the barnacle zone, browsing on small algae, and breathes through the lateral lobes of the foot, for the pallial cavity is very narrow and not specialized for respiration. Few of the characters of Otina are specialized; but most, particularly those of the digestive, genital and nervous systems, are primitive.

Dr. R. B. Clark and Dr. A. Milne have worked on the sublittoral bottom fauna of two sandy bays on the Isle of Cumbrae, using the Robertson mud bucket. 'Their studies were ehiefly on polychaetes, molluses, echinoderms and crustaceans. Few species in this area are gregarious; random distribution is the general rule in the bottom community. Drs. L. R. Fisher, S. K. Kon and S. Y. Thompson contribute their third study of vitamin $\mathbf{A}$ and carotenoids in invertebrates, and are here dealing with eleven species of euphausiids. There is considerable variation in the amount of vitamin A stored in the eyes. One small-eyed species, Thysanopoda acutifrons, is peculiar in having none. Neritic groups of Meganyctiphanes norvegica have higher reserves than those from the open Atlantic; but the fat concentration is highest in northern waters. Astaxanthin is found in all. It is significant that, despite their similar habitat, the euphausiids are biochemically and morphologically distinct from the Mysidacea, and in both respects appear to be related to the Penaeidea. Euphausiids form a link in the food-chains leading to blue and fin whales, sperm and bottle-nosed whales (through decapod cephalopods), herring, cod (at certain times of the year) and halibut. Dr. J. S. Alexandrowicz 
has extended his study of the innervation of the heart in Crustacea to that of Praunus. The three systems of nerve elements-intrinsic neurones (six in Praunus), a pair of nerves joining the local system to the central nervous system, and nerves to the arterial valves-are represented.

The salinity of Kames Bay sand, Isle of Cumbrae, with special reference to the distribution of Nereis diversicolor, has been investigated by Dr. Ralph I. Smith, of the University of California, Berkeley. He found a zone of relatively stable brackish interstitial water, and the zonation of the polychaete corresponds to this belt of lowered salinity. Whether it prefers the lowered salinity, or whether other competitive intertidal species shun it, is not yet clear; but Dr. Vera Fretter, working on the same species at Plymouth, shows that it can adjust itself gradually to the more dilute sea water and can maintain a steady state indefinitely. This it does by taking up water and losing salts. It achieves equilibrium in normal sea water, but is hypertonic in less salt water. Employing the tracer element sodium-24 obtained from the Atomic Energy Research Establishment, Harwell, she found that in sea water of 35 per mille salinity, saturated with oxygen, at normal atmospheric pressure and a temperature of $14^{\circ} \mathrm{C}$., the Nereis was in equilibrium, and the uptake of sodium averaged $250 \mathrm{mgm}$./hr./gm. wet weight. At half salinity, after accommodation to the dilution, the uptake averaged $160 \mathrm{mgm} . / \mathrm{hr} . / \mathrm{gm}$. wet weight, and at 9 per mille it was $180 \mathrm{mgm}$./ $/ \mathrm{hr}$./gm., there being an active uptake of salts in this last-named case against the concentration gradient. Oxygen deficiency and temperature changes also affect the rate of uptake of sodium. The integument of Perinereis cultrifera is more freely permeable to ions than that of Nereis diversicolor, the influx of sodium being about three times greater in normal sea water.

The number under review concludes with abstracts of memoirs recording work done at the Plymouth Laboratory of the Association and published in other journals.

N. B. Eares

\section{ISOTOPIC COMPOSITION OF METEORITIC HYDROGEN}

\section{By GEORGE EDWARDS}

\section{Institute for Nuclear Studies, University of Chicago}

$\mathrm{T}$

HE deuterium -protium ratio in meteorites is of interest because it is one of few known sources of information about the ratio of these isotopes in space near the time of formation of our planetary system. Their abundances in the sun's atmosphere are calculated from spectrographic measurements; but it is well known that at the sun's temperature deuterium is much more reactive in the nuclear process than hydrogen, and consequently there is extreme depletion of the deuterium as compared to the amount present in space.

The stony meteorites are too porous to retain a representative specimen of hydrogen gas, and if combined hydrogen is present it could rather easily be exchanged with hydrogen from water on the earth's surface after the fall. It appeared possible that hydrogen representative of that in planetary space might be retained in the carbonaceous chondrites (a small group of meteorites-twenty-one known, which contain varying amounts of free carbon and organic matter), and an investigation of the deuterium-protium ratio in this group of meteorites was carried out by G. Boato'. Previously, I. Friedman $^{2}$ conducted an isotopic analysis of an iron meteorite (Canyon Diablo); but stressed that some fractionation may have occurred during the process of outgassing the sample.

In 1953, I described ${ }^{3}$ experiments on the isolation and determination of protium and deuterium in iron meteorites and presented results for two meteorites. Since then a number of other meteorites have been examined by the same method.

The metal is oxidized by heating to $1,100^{\circ} \mathrm{C}$. in a stream of pure oxygen gas, the water from hydrogen in the meteorite being collected in a cold trap at $-70^{\circ} \mathrm{C}$. When the oxidation is complete, any carbon dioxide in the cold trap is pumped away. The temperature of the trap is raised, and the water vapour is passed over zinc granules at $400^{\circ} \mathrm{C}$. to regenerate hydrogen. The apparatus is so arranged that any unreacted water may be recycled and complete reaction assured. The hydrogen is compressed with a Toepler pump and its volume measured before isotopic analysis.

To obtain oxygen of the necessary purity for the oxidation, it is passed over a mixture of copper oxide and palladium asbestos at $700^{\circ}$ C., the oxidized products of hydrogen-containing compounds being adsorbed on active charcoal at $-135^{\circ} \mathrm{C}$.

The isotopic composition is measured with a 6-in. radius $60^{\circ}$-deflexion mass spectrometer of the double collector type similar to that described by Nier.4. The instrument is equipped with two capillary leaks and with magnetically operated valves permitting rapid change-over of the sample and a standard gas (see McKinney et al. ${ }^{5}$ ). Results are expressed as differences, $\delta \mathrm{D}$ per cent, between the deuterium concentration in the sample and standard. The relation between this difference and the absolute ratio is expressed by the equation

$\delta \mathrm{D}$ per cent $=\frac{\mathrm{D} / \mathrm{H} \text { sample }-\mathrm{D} / \mathrm{H} \text { standard }}{\mathrm{D} / \mathrm{H} \text { standard }} \times 100$

and the standard gas is hydrogen of Lake Michigan water, the absolute ratio of deuterium to hydrogen, $\mathrm{D} / \mathrm{H}$, being approximately $\mathbf{1} / 6,500$. Compared to this standard, average sea water is +4.5 per cent. The error in analysis (including deviations introduced during the conversion of water to hydrogen) is \pm 0.4 per cent maximum. The results of the analysis of a number of iron meteorites are shown in Table 1.

Meteorites were prepared for analysis as follows. With a diamond wheel in a dental drill apparatus, superficial rust was removed. Where sufficient rust was available, it was collected and the deuterium and protium determined in exactly the same way as for the meteorites. Final traces of rust were removed by sandblasting, after which the metal was washed with carbon tetrachloride. The meteorite was placed in a surface-grinding machine and dry-ground until no original surface metal remained and the specimen was rectangular in form. The meteorite was again washed in carbon tetrachloride and transferred with forceps to a shaping machine where the metal was cut to suitably sized swarf. All parts of the shaping machine around the meteorite were shrouded in 